no longer pink but whitish. It was not jelly-like and elevated but firm, cicatricial, and but slightly raised above the general corneal surface. There was less ptosis and he felt much more comfortable. The patient was kept under observation for some time and returned home much benefited. As an out-patient he used the following prescription with much advantage as an ointment: Hydrargyri oxidi Hlavi, 0.05 gramme; dionine, 0.05 gramme; and yellow vaseline, 5 grammes.

This case was a very severe one both as regards the lids and the cornea. It was probably too severe and too chronic for a cure to be expected. The condition of the lids and corneæ is well shown in the illustrations. When the redundant tissue had been reduced by operation, simple treatment with yellow oxide and atropine resulted in marked alleviation of the disease.

CAsE 2.-The patient, a male European, aged 14 years, first attended the hospital in October, 1905, and remained under observation for about nine months. The condition of the eyes had been first noticed some months before he attended. When first seen he presented the following condition. Each cornea was surrounded by a raised ring of pinkish-white tissue of a jelly-like consistency. Towards the centre of the cornea it was divided ap into ovoid discrete masses of translucent gelatinous material which coalesced centrifugally and merged into the ocular conjunctiva. This ring was about two millimetres wide at the widest part. The centre of the cornea was clear. The palpebral conjunctiva covering the lower lid was much

FiG. 3.

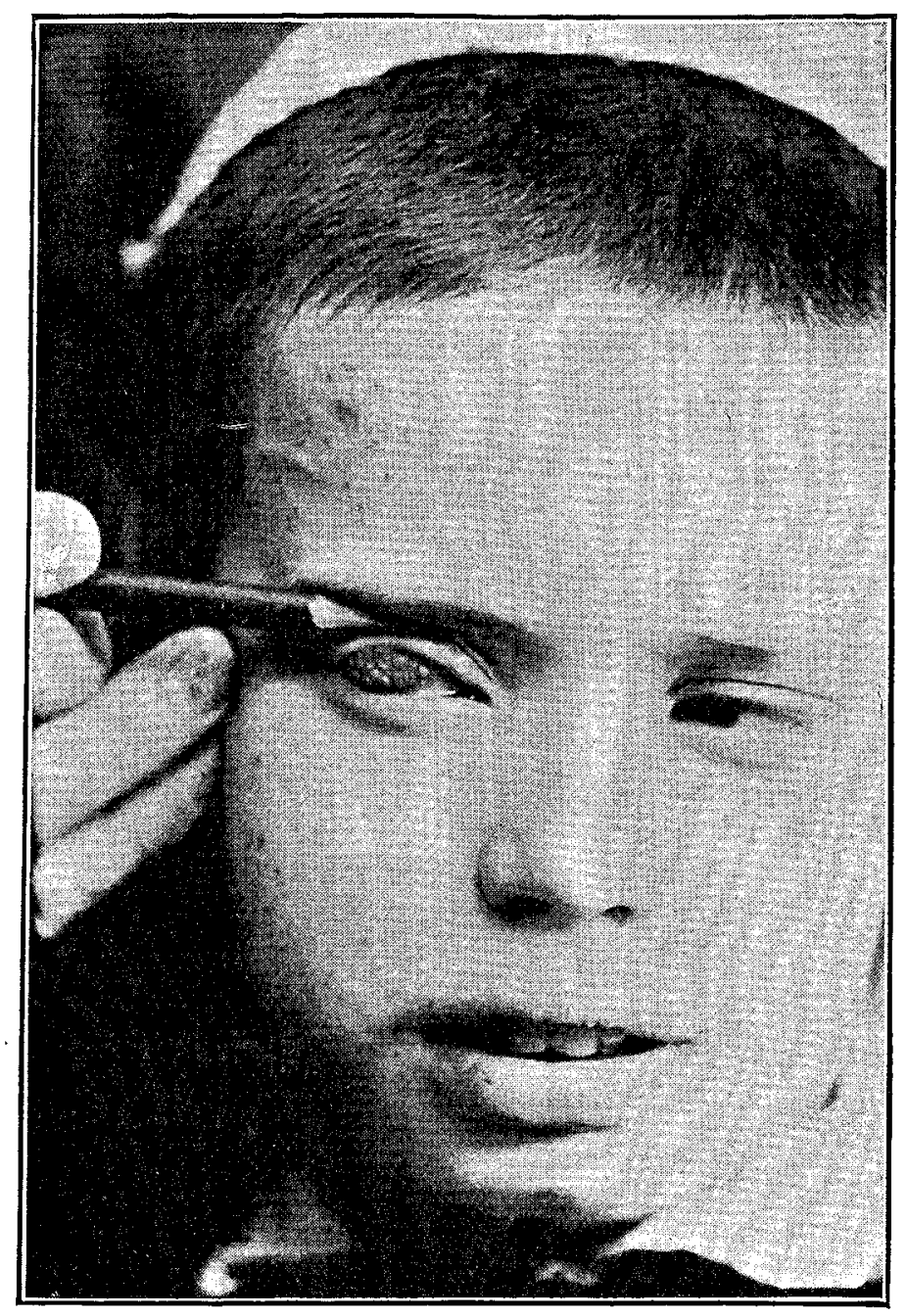

Showing flattened raspberry-like growth.

thickened and swollen. This thickening was continuous with a nodular thickened mass in the ocular conjunctiva and the lower cul-de-sac. This mass again merged into the pericorneal growth. The upper lids were thickened and the conjunctiva was congested and hard. It showed a fine tessellation but unless careful inspection was made this was not very obvious. There was on the right upper lid a flat sessile growth about three millimetres across. The patient complained of no subjective symptoms and the conjunctivæ were not injected. He was treated with 1 per cent. yellow oxide ointment well massaged in three times a day. After nine months of this treatment there was a very marked improvement. The pericorneal growth of the right eye had almost disappeared and the growth on the right lid could not be seen. A photograph taken at the end of nine months of treatment shows the pericorneal thickening and the nodular thickened condition of the conjunctiva. The localised thickening, now much less than formerly, can also be made out. In this case the stress of the disease fell upon the corneæ, the lids not being much affected.

CASE 3.-The patient, aged 11 years, was first seen in July, 1906. He was brought by his mother because his eyes were red. No history could be obtained of the condition being worse in summer nor did his mother know how long the disease had existed. Both upper lids were covered by large, hard granulations roughly hexagonal in shape. These are well-shown in the reproduced photograph of the everted lid. (Fig. 3.) Each cornea was surrounded by a very faint jelly-like ring of raised tissue, but it was so faint that were the lids not so typically affected it might easily be overlooked. The ocular conjunctivæ appeared to be normal. There was no injection of the conjunctivæ, but some lacrymation and photophobia were present. This case was treated for some time with the yellow oxide ointment combined with atropine. At the end of two months the condition was un. changed. The parents were averse to operative measures. In this patient the lids were severely affected, the cornea hardly at all.

- CASI 4.-The first three cases were all in young boys, but Case 4 was that of an adult Arab, aged 40 years, who came up for treatment in 1904. The left npper lid was covered with large cubical granulations arranged in short thick columns like a basaltic formation. Fach cube was about 1.5 millimetres square. The appearance of the lid was very similar to that of Case 3 , but the granulations were larger and deeper (more raised from the tarsus). The granulations were very hard and gritty to the touch. There was a large staphyloma involving nearly the whole of the cornea; the right cornea was nebulous. There was no typical affection of the cornea. The patient came to the hospital complaining more of the staphyloma than of the lid condition. The granulations were expressed with Knapp's roller forceps, but they were so hard and tough that great force was necessary to remove them. The lids were then treated with yellow oxide of mercury ointment. When last seen the lid was smooth and resembled a tiled pavement.

My experience has been that the treatment of spring catarrh is most unsatisfactory. I think that any pedunculated growth should be removed with scissors, large granulations with Knapp's roller forceps and Volkmann's spoon. Grady's forceps, excellent as the instrument is for expressing trachoma, will have little effect on the tough tissues in vernal catarrh. Such treatment, followed by the yellow oxide of mercury ointment well massaged in, has in my hands yielded the best results. I believe that copper sulphate does harm. At the present time I have a mild case under treatment with adrenalin which appears to me to have improved the condition.

\section{CLINICAL OBSERVATIONS ON THE ORIGIN OF FEVER.}

\section{BY ARNOLD LORAND, M.D. VIEN.}

From the moment of our birth we are constantly exposed to the incessant attacks of uncounted bacteria and to the effects of a large amount of poisonous material formed within our body or introduced from without, and if we survive this ceaseless battle it is due to the powerful weapon we possess in the internal secretion of the ductless glands, especially of the thyroid gland. That this gland possesses very energetic antitoxic properties can be shown by the fact that when it is extirpated animals or persons very readily acquire infectious diseases of all sorts. Thus, the late Professor Charrin (1) of Paris showed several years ago how readily dogs that have lost their thyroid succumb to all possible infections. Professor W. S. Greenfield (2) of Edinburgh has found that persons suffering from myxodema (athyroidia) very often die from tuberculosis, and Professor $\mathrm{Pel}(3)$ of Amsterdam found a great frequency of tuberculosis

I The parenthetical numbers throughout the article refer to the bibliography at the end. 
in the families of myzcedematous persons. This may be in connexion with the fact shown by Professor G. R. Murray (4) that the properties of the thyroid can be inherited.

As I showed at the last Congress of Tuberculosis in Paris (1905), tuberculosis is especially frequent as a sequel to any process deleterious to the thyroid gland, as after the puerperium, especially with prolongated lactation; after sexual excesses, as there is a relation between the sexual glands and the thyroid; after various infectious diseases; after rapid growth in puberty, due to hyperactivity of the thyroid which influences the growth of the body ; after severe diabetes due to exhaustion of the thyroid; and after previous hyperactivity in chronic alcoholism due to the action of alcohol upon the thyroid (5). On the other hand, all those agencies which excite thyroid activity may be a preventive against tuberculosis, such as raw meat (6) (7) (8) and milk. It is very probable that milk contains the internal secretion of the thyroid (9) (10) (11). This may also be shown by the fact that iodine, the main element of the thyroid gland, can reach the infant through the mother's milk and also by the observation that infants suffering from congenital myxcedema only begin to show the first symptoms of this condition after they have been weaned and never before. The iodine of the thyroid is contained in the colloid substance of the gland, and as infants and young animals have very little colloid substance as a rule, they receive the elements of thyroid secretion and also iodine through their mother's milk. Boiling the milk may thus deprive it of several important ferments and will make a "dead milk" out of a

"living" one. If it be true that milk has a bactericidal action this will only hold good for fresh milk, as is the case with blood serum.

The thyroid protects us against poisons of different origin such as the products of decomposition of protein food. This fact is shown by the experiments of Dr. Leo Breisacher of Detroit (6), formerly assistant of the late Professor Munk of Bérlin, and from those of Dr. Blum (7) of Frankfort. The experimental results of Dr. Chalmers Watson (8), showing alteration of the thyroid in certain animals after an exclusive diet of raw meat, and those of Dr. D. Forsyth (12) concerning the pituitary body in some animals, may be in connexion with this fact. As is well known, the thyroid and pituitary body stand in very close relationship. Galeotti and Lindemann (13), in 1897, have also shown that the products of decomposition of meat produce an increase of the colloid substance of the thyroid.

The antitoxic properties of the thyroid against different products is also shown by the observations of Lanz (14) and Walter Edmunds (15), who have found that animals without thyroid resist narcosis badly, and, as I have shown in a com. munication to the Paris Biological Society (16), chloroform, like alcohol, produces a condition of byperactivity in the thyroid gland, which results also in an excited mental condi. tion. The observation that cases of Graves's disease and of severe diabetes cannot stand narcosis may be related to this fact.

It has been shown recently by Hunt (17) that the thyroid protects us against poisons like acetonitril and that iodine acts through the thyroid. Garnier (18) of Paris has found that certain chemical products, such as iodine, produce great alterations in the thyroid. As is well known, cases of Graves's disease (hyperthyroidia) have been observed after iodine treatment. The following observations make it appear probable that the thyroid may also play a protective rôle against infectious diseases. This may already be considered proved by the fac: that, as Roger and Garnier (19), Crispin (20), Torre (21), Bayon (22) of Würzburg, de Quervain, and others have found, the thyroid is, as a rule, altered in infectious diseases. As Roger and Garnier (19) have shown by a series of investigations confirmed by the above-named authors, the thyroid shows in acute infections diseases with fever an increased activity with enlargement of the folliculi, which are filled with a large quantity of colloid substance which may even enter into the adjacent lymphatic spaces. However, this hyperactivity of the thyroid gland may be followed by its exhaustion and thus after a certain duration of high fever there may be no colloid substance at all in the folliculi.

It is only logical to suppose that to anatomo-pathological alterations of the thyroid, indicating a condition of hyperactivity, there must be corresponding clinical symptoms and that these must necessarily be similar to those found in another condition of hyperactivity of the thyroid glandi.e., in Graves's disease, the condition of hyperthyroidia

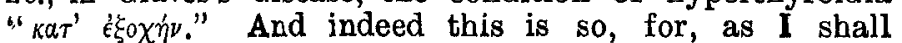

try to show, fever and Graves's disease have similar clinica symptoms. Thus their most typical symptom is the same: tachycardia or increased frequency of the pulse, without which no case of Graves's disease should be diagnosed. There is a sensation of heat in most of the cases of Graves's disease and the temperature sometimes reaches a dangerous degree in fully developed cases of this disorder. Thirst frequent in fever, is also a frequent symptom in Graves's disease (polydipsia in 14 out of 59 cases recorded by Albert Kocher (23) ), and can also be produced by thyroid feeding (Lanz (24), Georgiewski (23)), and others. After a certain duration of fever further symptoms of an increased activity of the thyroid appear, such as abundant perspiration-a typical feature of Grazes's disease. Vaso-dilatation and excessive perspiration can also be produced by thyroid feeding. The latter symptom of fever is a device by which nature tries to eliminate toxic products, and accordingly there generally follow upon it a fall in the temperature and an amelioration of the symptoms of fever. The diarrhoea which we find in some infectious diseases, like that of typhoid fever, trypanosomiasis, \&c., is also a typical symptom in Graves's disease. When the fever subsides there appears another typical symptom of this condition, polyuria. To complete this analogy I may mention toxic decomposition of proteins, diminution in the body weight, great muscular weakness, and increased elimination of urea and uric acid as typical symptoms of both conditions. As in Graves's disease, there is also in fever an augmentation of the processes of oxidation. Glycosuria is frequent in both conditions and acetonuria may occur in fever and also in Graves's disease. Glycosuria and diabetes in consequence of infectious diseases are, as I have shown in a paper read before the London Pathological Society (26) probably due to the increased activity of the thyroid, and their disappearance occasionally after a high fever may be ascribed to the exhaustion of the thyroid after a previous hyperactivity. We know that a condition of Graves's disease may be followed by a myxœdematous condition in which, as I have shown previously, glycosuria is very rare. In the few hitherto published cases there was no complete myxodema.

Both in Graves's disease and fever there is an augmentation of the processes of oxidation. After convalescence, however, oxidation may be diminished, and this explains, as I have shown at the French Congress of Medicine in 1904 (27), why obesity so frequently occurs after infectious diseases on the basis of degenerative changes of the thyroid, which governs oxidation: during the course of infections disease with fever increased activity of the thyroid and loss of weight occur, and these are followed by exhaustion of thyroid activity and obesity.

The conditions of delirium and maniacal exaltation in cases of high fever are analogous to the condition of mental exaltation that may occur in Graves's disease. According to the late Moebius (28), in cases of Graves's disease there are sometimes symptoms like those of alcoholic intoxication due to the toxins of the thyroid. I believe that the mental exaltation in chloroform narcosis and alcoholic intoxication stands in relation with the action of these drugs upon the thyroid. That alcohol acts upon the thyroid has been shown by de Quervain (5), Hertoghe (29), and others.

Cataneous eruptions may occur in fever or in Graves's disease. In the same way as in many skin diseases they may be considered as the expression of an elimination of toxic products through the skin. For we must remember that the skin is not only a respiratory organ but also besides the kidneys are our most important eliminatory organ for toxic products. When a dog is varnished all over its body it invariahly dies from auto-intoxisation. If persons burned on large surfaces of their body die in the same way, it may be due to a certain degree to the ointments, sticking plasters, and bandages through which no air can penetrate. When these persons are kept in water or even dry but without any bandage or clothing on, as I have seen in the wards of Dr. Sneve in Minneapolis, they may remain alive. Tonsillitis is frequent in infectious diseases and also in Graves's disease.

All the above symptoms of fever may be considered as expression of the efforts of nature to defend herself by eliminating toxic products. All toxic products which are the causes of infection act upon the thyroid gland, which by its increased activity produces symptoms such as we see in Graves's disease. That these symptoms, especially abundant perspiration, polyuria, and diarrhoea, typical in some infectious diseases, may be considered as the direct consequence of thyroid activity can be best shown by the fact that the 
thyroid gland governs the functions of the skin, intestines, and kidneys. When the thyroid is extirpated or degenerated as in myxodema all these symptoms are diminished and they are much augmented in the opposite condition in Graves's disease. In a communication to the Paris Biological Society on Feb. 25th, 1907, I showed that the thyroid and kidneys stand in very close relationship and that gout may be produced by thyroid degeneration and subsequent alteration of the kidneys by which uric acid is retained. By thyroid treatment we can powerfully augment the elimination of uric acid, and by such a medication the quantity of urine is augmented and it contains a higher proportion of solids with a higher specific gravity. In myscedema there are very often oliguria and retention of the solids. In Graves's disease and fever there is an augmented elimination of uric acid and also often in diabetes (hyper thyroidia).

That the symptoms of fever may be considered as due to increased thyroid activity is also shown by the fact that nearly all such symptoms may be produced by thyroid preparations. I have personally taken for experimental purposes during ten months thyroid tablets and experienced the sensation of heat, flushings, and abundant perspiration. It is interesting to note that all kinds of wounds and contusions I got during the time I took these tablets healed with surprising rapidity with fine granulations far better than previonsly; on the other hand, I very frequently suffered from tonsillitis and acne eruptions.

Symptom 3 similar to fever have also been produced in animals by thyroid feeding - thus very often elevation of the frequency of the pulse trom 100 to 140-160 beats (Lanz), and from 150 to 200 beats (Georgiewsky), whilst Ballet and Enriquez (30) produced regular fever in their animals; Easterbrook (31) also produced "some pyrexia" in his animals and an increase of pulse-rate of about 40 a minute. As Dr. Tanberg, former assistant of the Physiological Institute in Cbristiania, told me, he has produced an increase of the temperature of two and a balf degrees in animals the thyroid of which he has extirpated, after giving very large quantities of thyroid gland.

It is of great interest to the questicn at issue that the remedies which we employ to fight fever should also produce symptoms like the thyroid does when it is in increased activity. Thus salicylates produce a vaso-dilatation and abundant perspiration and afterwards diminution of the temperature. I have myself taken salicylates or acetonitril preparation and felt the sensation of heat and afterwards perspiration. When we take a hot air or steam bath for cold or gouty pains we produce first great heat, tachycardia, and then abundant perspiration, and the typical symptoms of fever, or increased thyroid activity.

We know that certain drugs, as found by Garnier (18), have an exciting action upon the thyroid, such as iodine, and what is especially important, pilocarpine. The great sudorific action of this drug may stand in some relation to its effect upon the thyroid. It lies very near to suppose that the different drugs which antagonise fever do so by acting first upon the thyroid gland and exciting its increased activity to fight infection. But if we gave too much of these we might exhaust its activity in the same way as Garnier (18) found an exhaustion of the colloid of the thyroid after too much iodine. This shows that we should not give antipyretics in too large doses. We should excite thyroid activity but not overdo it.

That the thyroid is able to protect us against infectious diseases can be best shown by the fact that it exercises a certain influence upon phagocytosis. When the thyroid is extirpated or degenerated the red blood corpuscles are diminished; and after thyroid treatment they are much augmented. After the extirpation of the thyroid there is first hyperleucocytosis which, according to certain authors, is followed by hypoleucocytosis. Quite recently Mdlle. Fassin (30) has shown in experiments made in the laboratory of the Royal University of Liège that after extirpation of the thyroid tbere is a checking of the production of alexins. In a discussion on internal secretions a few years ago in one of the London medical societies Sir A. E. Wright insisted upon the importance of internal secretions upon the production of opsonins. Fever can be produced with similar symptoms by toxic products of different origin, as from small elements of the vegetable kingdom like bacteria, certain plants, and even fruits, as is shown by the urticaria which follows in some persons after eating strawberries. Certain minute elements of the animal kingdom have a similar power, such as protozoa like trypanosomes, and we may also instance certain kinds of animal food like oysters in regard to some persons, the poison of snakes, and certain insects like tarantels and scorpions. Besides these poisons coming from without, fever with similar symptoms can also be produced by, poisons formed within our body by the hyperactivity of a gland-the thyroid. When so many different poisons produce the same result it lies near to suppose that they do this by means of the same agency, which, according to the aforesaid observations, is very probably a thyroid byperactivity.

As is well known, a condition of hyperactivity of the thyroid may be followed by its exhaustion and thus Graves's disease may often be followed by myxoedema athyroidia. In the same way the hyperactivity of the thyroid gland in infectious diseases may also be followed by its exhaustion and a myxœdematous condition. Even complete myxœdema most. frequently appears after a previous infectious disease-a fact recognised by the earliest Finglish authors on this disease. Accordingly, it is not surprising if an infectious disease like trypanosomiasis is followed by a condition like sleeping sickness, which, as I have shown at the German Congress for Internal Medicine in 1905, presents all the clinical symptoms of, and identical anatomico-pathological alterations of the central nervons system with, myxcedema. On the other hand, trypanosomiasis presents all the typical symptoms of Graves's disease. In syphilis also after the fever with eruptions in the secondary stage, in which we not infrequently see, especially in women, a swelling of the thyroid, we find in the tertiary stage many symptoms of a condition of myzodema or hypothyroidia and with the iodine treatment we are introducing the main element of the thyroid gland. Iodine is also especially active, if not given in too large doses, in exciting thyroid activity, and sometimes it even provokes Graves's disease. With the atoxpl treatment we are giving another main element of the thyroid-i.e., arsenic.

Persons of healthy constitution with a good working thyroid may get the sensation of heat and perspiration spontaneously after a cold or gouty pains, even without salicylates, and feel better afterwards, whereas persons with a deficient thyroid have difficulty in producing the symptoms of fever. Just lately I bave observed a young man, aged 22 years, with symptoms of hypothyroidia as described by Hertoghe (29) who bad follicular tonsillitis. He presented none of the symptoms of fever, but it took him ten days to get over it and he felt very weak afterwards. There was this summer an epidemic of typhoid fever in the lunatic asylum of Colorno, near Padua. I have it from Dr. Gassenghi, of the University of Padua, that half of the patients died, but it is very interesting to note that there was no fever. This may stand in relation with the fact that many cases of insanity and idiocy stand in etiological relation to alterations of the thyroid gland. I feel sorry not to be able to enter more fully upon this interesting subject, but I may shortly mention that, as I have stated in the Neurological Societs of New York (A pril 2nd, 1906 ', I have observed several cases of dementia præcox and melancholia with alterations of the thyroid and sexual glands in each case. Alcoholics suffering from pneu. monia seldom get high fever, but often die in a short time. Alcohol in large quantities not only causes degenerative changes in the heart but also in the thyroid. And we should not forget that there exist very close relations between the activity of these two organs.

It seems to follow from these observations that persons with a good sound thyroid have a better chance in fighting infections and intoxications than persons with a degenerated thyroid. In persons with an active thyroid, an increased activity of the gland, and thus a better functioning of the eliminative organs which are governed by it, can take place more easily than in persons with a degenerated thyroid and in consequence with a dry skin, constipated bowels, and lazy kidneys. Some hints may be derived from these observations in the interest of prophylaxis and prognosis and also for the purposes of life insurance.

It seems to me that the conclusion is not unjustified, that fever is a beneficent institution of our organism which is produced by an increased activity of the thyroid gland as a reaction against toxic products and poisons in general. The symptoms of fever are the expression of this increased activity and they are directed towards the elimination of noxious elements. It would be unreasonable to oppose this spontaneous healing tendency of nature by fighting these salutary symptoms, unless there be byperpyrexia. Fever, as 
probably disease in general, serves the ends of nature in the interest of our conservation.

Bibliography. - 1. Charrin : Les Defenses Naturelles de l'Organisme, Paris, 1898 (Masson). 2. Greenfield : auoted after Lwald, Die Lirkrankungen der Schilddriise. Nothnagel's Handhuch, Wien. 1896, p. 159. 3. Pel: Myxcedema, Volkmann's Sammlung Klinischer, Vorträge, 1895, No. 123. 4. Murray: Diseases of the Thyroid Gland, Part I., London, 1901. 5. De Quervain : Semaine Medicale, 1905. 6. Breisacher: Untersuchung iber die Gland Thyroidea, Archiv ftir Anatomie und
Physiologie, Supplement Band, 1889. p. 509. 7. Blum : Pfitiger's Physiologie, Supplement Band, 1889. p. 509. 7. Blum : Pflitger's Archiv, 1902, vol. xc., p. 285; Archiv fur die Gesammte Physiologie, $1902, \mathrm{p} .617 .2$. Chalmers Watson : THE LANCET, Feb. 11th, 1905, p. 347. 9. Bang: Ueber die Ausscheidung des Iodothyrins durch die Milch, Berliner Klinische Wochenschrift, Dec. 27th, 1897. 10. Mosse: Académie de Médecine, 1898. 11. Jeandelise : Linsuffisance Thyroidienne et Parathyroidienne, Paris, 1904. 12. Forsyth: THe LANCET, Jan. 19th, 1907. p. 154. 13. Lindemann: Virchow's Archiv 1897, p. 202. 14. Lanz: Zur Schilddriisenfrage, 1894, Leipzig. 15. W Gdmunds: THE LANCET, May 11th (p. 1317), 18th (p. 1381), 25th (p. 1449) 1901. 16. Lorand: Comptes Rendus de la Société de Biologie, 1906 17. Hunt: International Congress of Physiology, Heidelberg, 1907. 18. Garnier : La Thyroide dans les Maladies Infectieuses, These de Paris, 1899. 19. Roger et Garnier : Presse Médicale, April 19th, 1899. 20. Crespin: Giornale dell' Associazione Napolitano di Medici, xii., 3. 21 Iorre: La liroide nel Morbi Infettivi, Il Policlinico, No. 6, p. 145; No. 8 p. 226; No. 10, p. 280. 22. Bayon: Würzburger Abhandlungen, 1904 23. A. Kocher : Mittheilungen aus den Grenzgebieten, \&c., 1901. 24 Lanz : quoted after Buschau, Wien, 1895. 25. Georgiewski : Zeitschrift für Klinische Medicin, 1897, Band xxxiii., f. 1-2, p. 153. 26. Lorand Iransactions of the Pathological Society of London, vol. lvii., part 1 , Moebius: Die Basedow'sche Krankheit, Nothnagel's Handbuch, II. edition. 29. Hertoghe : Die Rolle der Schilddrüse, \&c, München, 1900, and Paludisme et Myxœdèm, Progrès Médical Belge, No. 2, 1902 30. Ballet and Enriquez: quoted after Buschau. 31. Easterbrook THE LANCET, August 27th, 1898, p. 546. 32. Fassin: quoted after Zentralblatt für die Physiologie und Pathologie des Stoffwechsels, 1907.

Christiania, Norway

\section{FOUR CASES OF TUBERCULOUS DISEASE OF THE TEMPORAL BONE.}

BY C. ERNEST WEST, F.R.C.S. ENG.,

ASSISTANT AURAL SURGEON TO S'1. BARTHOLOMEW'S HOSPITAI.

IT is just three years since the first of a series of four cases of undoubted tuberculous disease of the petrous came under my care. They form a fairly homogeneous group, all occurring in children, and none showing any evidence of pulmonary infection. The comparatively recent death of two of the four cases has been an interesting disappointment and has, I think, in a sense rather added to the significance of these cases. I shall give the four cases briefly and shall then comment on some points about them.

CASE 1. - The patient, a female child, aged 11 years, was admitted into St. Bartholomew's Hospital on Sept. 2nd, 1904, for headache and vomiting. The history of the case showed that the left mastoid was operated on at a children's hospital seven years previously without cessation of discharge which had continued ever since. Some months ago an abscess formed and burst through the scar. The child had been ill for the last two days with frequent vomiting, severe frontal headache, and general pains in the head. On admission the temperature was $100 \cdot 8^{\circ} \mathrm{F}$. and the pulse was 140. The tongue was dirty and the child looked ill. There was a sinus over the left mastoid, the surrounding skin being undermined and bluish. An operation was pertormed on the same day. The old scar was reopened. The surface of the posterior part of the mastoid region was bare and eroded. An old cavity in the mastoid was filled by a caseous mass. There was a fistula of the external semicircular canal. A probe introduced into the posterior limb passed out into the dura mater on the posterior surface of the petrous. The external canal was followed up by a burr. A tuberculous abscess was found connected with it and bounded posteriorly by the dura mater. The superior canal was found to be enlarged on its convexity into a caseous abscess. The vestibule was opened up above the facial nerve and cleared out. The walls of the mastoid cavity were softened and a large removal of bone was made, exposing a part of the descending portion of the facial nerve. The tympanum was cleared out and the vestibule and cochlea were opened and the whole promontory burred away, leaving the nerve spanning the cavity in a narrow bridge of bone. A large concho-meatal flap was cut and turned upwards. The cavity was packed with ganze from in front and well drained behind.

Result.-There was no facial paresis. The whole cavity became completely healed until December, 1904, when a small amount of discharge brought the patient back to the hospital. It came from a small cavity in the floor of the bony meatus. This was thoroughly scraped and healed in about a fortnight. The patient was seen on Oct. 1st, 1907, when the ear was perfectly sound.

CASE 2.-The patient, a male child, aged two years, of healthy appearance. was admitted into the hospital on August 26th, 1905, with chronic discharge from the right ear and a sinus over the right mastoid and glandular cold abscess below the angle of the right jaw. At the operation there was found underlying the sinus a spongy sequestrum consisting of the roof and posterior wall of the meatus and the whole of the mastoid. This was loose and was removed. The cavity left was walled in by flabby, pale granulation tissue which lay above and behind upon the exposed dura mater. There was only a small amount of softening of the bony parts of the cavity wall. A radical operation was done and the abscess in the neck was opened, scraped, and stitched up.

Result. - The whole cavity did remarkably well and rapidly became completely dry. The incision in the neck healed by first intention and there was no recurrence of the abscess.

This boy was readmitted to the hospital in September, 1907, with symptoms af tuberculous meningitis. The mastoid operation had been a complete surgical success and was quite dry. He died in about three weeks and the necropsy showed a typical tuberculous meningitis. Post mortem, careful examination of the petrous showed that there was no trace of disease present in it.

CASE 3.- The patient, a male child, aged four years, was admitted into the hospital on Oct. 24th, 1905, with left mastoid abscess. There was an indefinite history as regards the duration of the left otorrhœea. A swelling behind the ear had been noticed for one week. On admission the temperature was $97^{\circ} \mathrm{F}$. There was a lax, fluctuating swelling on and above the left mastoid, without redness or cedema. The meatus was blocked by granulation tissue. At the operation there was found to be a communication between the superficial abscess and the interior of the mastoid. The mastoid was filled by granulation tissue and the cavity was bounded by dura mater above and behind. The layer of granulation tissue on the dura mater extended some way beyond the exposed area of the membrane. A very extensive operation was carried out on the petrous and completed in the usual way. The nerve was found to be exposed in the tympanic part.

Result.-The whole cavity was soundly healed by the beginning of December, 1905. Histologically the granulation tissue showed typical tuberculous systems. The patient was seen on Oct. 16th, 1907, when the ear was perfectly dry and sound. There was no enlargement of the glands in the neck.

CASE 4.-The patient, a male child, one year old, was admitted to the hospital on April 18th, 1906. There was a history of discharge from the left ear since shortly after birth. On April 10th a sequestrum, formed apparently by a part of the base of the petrous, had been removed through the left meatus. The lymphatic glands over the mastoid and those in the posterior triangle of the neck were enlarged and there was a cold abscess in the neck. A radical operation was done on April 20th. The base of the petrous was extensively softened and infiltrated by granulation tissue. The tympanum was filled by caseating tubercle which extended forward along the Eustachian tube to the apex of the petrous and was markedly more degenerate anteriorly. There was a button of granulations about the fenestra ovalis which was continuous with a mass filling the vestibule. The window was enlarged and the vestibule was cleared out. The cochlea was not obviously involved. The abscess in the neck was opened, scraped, and sutured.

Result.-The ear did well and the cavity was completely healed in about six weeks. The wound in the neck healed by first intention but subsequently reopened and a further operation on the tuberculous glands became necessary. For sorne time the child used to fall over on his left side when sat up in bed, but this disappeared in a few weeks. A guinea-pig inoculated with the tympanic granulations developed typical tuberculosis.

In January, 1907, the patient was brought back to the hospital with a very large mass of glands in the left side of the neck. The ear was quite dry and sound. A very extensive operation was performed on the side of the neck in one of the general wards, but the wound became tuberculous and the child succumbed to a rapid spread of the disease. 